\title{
RANCANG BANGUN SISTEM MONITORING JARINGAN ACCESS POINT MENGGUNAKAN SIMPLE NETWORK MANAGEMENT PROTOCOL (SNMP) BERBASIS WEB
}

\author{
Panji Kukuh Prayogi ${ }^{1}$, Mira Orisa ${ }^{2}$, FX Ariwibisono ${ }^{3}$. \\ Program Studi Teknik Informatika S1, Fakultas Teknologi Industri \\ Institut Teknologi Nasional Malang, Jalan Raya Karanglo km 2 Malang, Indonesia \\ Panji.kukuh76@gmail.com
}

\begin{abstract}
ABSTRAK
Proses monitoring jaringan access point terkadang membuat penyedia layanan harus selalu mendatangi titik access point untuk melakukan controlling. Tidak akan menjadi masalah apabila titik layanan access point hanya 1, namun jika dalam sekala yang cukup besar maka hal ini tentu akan menyita waktu cukup banyak. belum lagi administrator juga harus selalu mematikan dan menghidupkan perangkat guna mereset data cache nya setiap minggu.

Untuk memecahkan masalah tersebut usaha yang dilakukan adalah dengan membangun sistem monitor access point menggunakan protokol sederhana yaitu dengan Simple Network Management Protocol(SNMP). Sistem monitoring jaringan access point menggunakan protokol SNMP merupakan sebuah rancangan sistem yang dapat membantu penyedia layanan access internet untuk memonitor kondisi access point di beberapa titik.

Dengan adanya system monitoring ini penyedia layanan dapat melakukan controling dan monitoring jaringan berskala cukup besar tanpa harus mendatangi titik hotspot nya satu persatu. Hasil pengujian dari sistem monitoring jaringan access point menggunakan Simple Network Management Protocol(SNMP) dapat disimpulkan bahwa sistem berjalan dengan hasil yang cukup baik dan sesuai harapan. pengujian terhadap progam juga dilakukan melalui beberapa peramban yang umum seperti Mozilla Firefox, Microsoft Edge dan Google Chrome. Pengujian sistem juga dilakukan pada beberapa sistem operasi, yaitu windows, linux serta Android.
\end{abstract}

Kata kunci : Sistem Monitoring Jaringan Access Point, Simple Network Management Protocol(SNMP), mikrotik.

\section{PENDAHULUAN}

Institut merupakan sebuah sekolah tinggi teknik dengan banyak sekali jurusannya. Dengan banyaknya jurusan ini maka disebuah institut sangat mungkin kebutuhan jaringan atau wifi banyak yang membutuhkan. Saat ini semua proses mengajar juga saling membutuhkan koneksi bahkan untuk ujian sekalipun. Institut Teknologi Nasional Malang adalah salah satu pengguna jaringan komputer dengan lebih dari satu gedung yang saling terhubung dengan gedung lainnya.

Pada Institut Teknologi Nasional Malang telah memiliki sebuah titik access point lebih dari enam belas buah perangkat. Dengan banyaknya perangkat ini memungkinkan seorang admin harus bisa mengatasi masalah pada access point di tiap-tiap gedung. Dengan jarak yang cukup luas dan panjang antar gedung membuat pengawasan cukup sulit karena harus mengecek satu persatu. Oleh karena itu saya peneliti ingin membuat sistem yang berguna bagi admin jaringan di Institut Teknologi Nasional Malang.

Monitoring jaringan adalah suatu cara manajemen jaringan membutuhkan penggunaan perangkat lunak dan perangkat keras. Perangkat lunak digunakan untuk mengelola proses pemantauan (monitoring) terhadap fungsi dan kehandalan jaringan yang terdiri dari lalu lintas (traffic) dalam ukuran penggunaan lebar saluran data atau biasa disebut bandwith.
Dalam suatu jaringan terdapat protocol jaringan yang umum digunakan yaitu Simple Network Management Protocol (SNMP), untuk melakukan manajemen perangkat yang terhubung dalam jaringan IP (Internet Protocol). perangkat jaringan tersebut antara lain switch, router, modem, komputer, server dan lain-lain. Sistem kerja dari Simple Network Management Protocol (SNMP) adalah dengan menggunakan data-data dari komunikasi UDP dengan device/peralatan yang tersambung dalam jaringan tersebut. Fitur yang dimiliki oleh protocol Simple Network Management Protocol (SNMP) yaitu melakukan pertukaran data ataupun melakukan setting kepada peralatan yang terkoneksi jaringan. Bagi administrator jaringan protokol ini sangat membantu untuk memonitor dan mengontrol jaringan.

Simple Network Management Protocol (SNMP) menjadi basis pembuatan perangkat lunak manajemen jaringan, dikarenakan dapat memberikan kerangka manajemen standar untuk setiap merk komponen jaringan dan pengembang aplikasi jaringan. Hasil akhirnya adalah aplikasi manajemen jaringan yang mengimplementasikan SNMP dapat memonitor semua perangkat yang memiliki fitur SNMP.

Dengan menggabungkan Simple Network Management Protocol (SNMP) dengan teknologi web saat ini, administrator jaringan akan lebih mudah dalam memonitor dan mengontrol perangkat jaringan 
melalui website. Administrator jaringan juga dapat memonitor melalui ponsel pintar dikarenakan tampilan yang responsive dan menarik.

Berdasarkan uraian di atas maka pada tugas akhir ini, akan dibuat sistem Monitoring Access Point menggunakan Simple Network Management Protocol (SNMP) berbasis Web, Sistem ini dapat mempermudah network administrator untuk memonitoring perangkat Access Point yang digunakan.

\section{TINJAUAN PUSTAKA}

\subsection{Penelitian Terdahulu}

Semakin bertambahnya ukuran dan jumlah perangkat jaringan akan semakin kompleks masalah yang akan dihadapi pada jaringan tersebut. Sehingga perlu pengawasan pada jaringan secara terus-menerus untuk menjamin ketersediaan atau availability layanan. Simple Network Management Protocol adalah Protokol yang dapat digunakan untuk memonitor dan melakukan menagemen jaringan. Protokol ini mendapatkan informasi dari pertukaran sandi komunitas yang nantinya akan memberi jawaban status dan keadaan dari suatu Perangkat jaringan. layer transport yang digunakan pada protocol ini adalah UDP pada port 161.[1]

Monitoring jaringan merupakan sebuah bentuk kegiatan untuk mengatur sistem jaringan yang berada pada wilayah atau tempat tertentu yang memanfaatkan topologi jaringan. Pemantauan secara real time dilakukan untuk memperoleh data mengenai kondisi jaringan, informasi akan disampaikan pada client apa masalah yang menyebabkan jaringan mengalmi gangguan dan mengirimkan pesan melalu telegram tersebut. Pesan yang disampaikan yaitu berupa informasi up-down pada suatu jaringan, pengaktifan koneksi jaringan dan lain sebagian. Dengan menggunakan aplikasi telegram merupakan solusi yang tepat untuk mengatur jaringan dalam memonitor bandwidth disebuah jaringan. [2]

Terdapat dua macam Teknik modulasi dari WLAN, yaitu Orthogonal Frequency Division Multiplexing (OFDM) dan Direct Sequence Spread Spectrum (DSSS). Standar protolol WLAN adalah 802.11 yang ditetapkan oleh badan standar IEEE pada akhir tahun 1990. Jenis-jenis Standar 802.11 terbagi menjadi beberapa jenis, yakni 802.11, 802.11b, dan $802.11 \mathrm{~g}$ yang membedakan secara umum adalah frekuensi dan kecepatannya.[3]

Suatu perusahaan atau instansi pemerintah terdiri dari beberapa bagian atau divisi yang saling berkaitan satu dengan yang lainnya. Dengan semakin besarnya skala jaringan suatu perusahaan, maka semakin besar pula resiko untuk memantau tiap saat. Hal ini menyebabkan semakin besarnya sumber daya yang diperlukan untuk membangun jaringan tersebut, serta kualitas jaringan yang mungkin menurun akibat traffic - lalu lintas data yang tinggi. Seorang network administrator harus selalu memonitor jaringan yang di kelolanya untuk mengetahui kondisi jaringan apakah mengalami masalah atau tidak. [4]
SNMP merupakan protokol perangkat lunak manajemen jaringan dan bukan merupakan perangkat lunak jaringan. kondisi jaringan dapat dikatakan berfungsi secara maksimal apabila rutin untuk melakukan monitoring perangkat jaringan, seperti objek penelitian monitoring perangkat jaringan berbasis web menggunakan protocol SNMP yang bertujuan mempermudah tugas administrator dalam melakukan monitoring jaringan.[5]

SNMP merupakan suatu sistem manajemen yang penting untuk memantau dan mengumpulkan informasi suatu jaringan. Dengan pemantauan dan pengumpulan informasi tersebut dapat dilakukan analisis. Salah satu metode analisis adalah analisis jangka pendek (short-term analysis) yang berguna untuk mendeteksi dan membuat perbaikan secara cepat atas kesalahan dan masalah yang timbul. Dengan demikian kualitas jaringan dapat memenuhi Quality of Service (QoS) yang lebih baik.[6]

\subsection{Monitoring Jaringan}

Monitoring Jaringan merupakan kegiatan yang dilakukan untuk mengelola suatu sistem jaringan di lokasi tertentu dengan topologi jaringan tertentu. Sistem monitoring jaringan ini digunakan untuk mempermudah tim teknis dalam melakukan pemeliharaan dan pemantauan secara rutin kondisi jaringan di lapangan.[7]

tahapan dalam sebuah sistem monitoring terbagi ke dalam tiga proses besar:

1. Proses pengumpoulan data untuk dilakukan monitoring.

2. Proses melakukan analisis terhadap data yang diperoleh

3. Proses menampilkan data olahan monitoring

\subsection{Access Point (AP)}

Access point $(A P)$ merupakan sebuah perangkat yang bertugas mengatur dan menghubungkan koneksi beberapa peralatan Wi-Fi. AP dapat dianalogikan dengan switch, hanya saja digunakan pada wireless LAN. AP juga dapat menghubungkan wireless LAN dengan wired LAN. Selain sebagai pusat jaringan wireless sebuah AP biasanya juga mempunyai port UTP yang bisa digunakan untuk berhubungan langsung dengan jaringan Ethernet yang telah ada. [8]

\subsection{Simple Network Management Protocol (SNMP) \\ SNMP adalah merupakan protokol jaringan} pada TCP/IP berfungsi untuk menangani monitoring sekaligun manajemen jaringan. Protokol SNMP melakukan pengumpulan dan memanipulasi informasi jaringan yang berharga dari switch, router, server, printer, dan perangkat lain yang terhubung ke jaringan..[9] Protokol SNMP pada jaringan menggunakan layer transport UDP. Pada sistem monitoring jaringan dengan menggunakan protokol SNMP, mempunyai tiga komponen dasar antara lain: 
1. Manajer SNMP adalah perangkat utama yang melakukan proses dan menangani tugas-tugas manajemen jaringan.

2. Agen SNMP adalah perangkat pada jaringan yang akan diamati dan dikelola. setiap agen akan merespon dan menjawab permintaan manajer SNMP.

\subsection{Mikrotik}

MikroTik RouterOS ${ }^{\mathrm{TM}}$,merupakan sistem operasi Linux base yang diperuntukkan sebagai network router. Untuk mempermudah pengaturan dalam system operasi mikrotik ini, digunakan aplikasi winbox yang dapat diakses pada system operasi windows..[10]

\subsection{Open System Interconnection (OSI)}

Open System Interconnection (OSI) adalah suatu standar komunikasi yang terdiri dari tujuh etintas atau layer. Ketujuh layer tersebut mempunyai fitur atau fungis dalam jaringan yang berbeda satu dengan yang lainnya. Setiap layer bertanggung jawab secara khusus pada proses komunikasi data.[11]

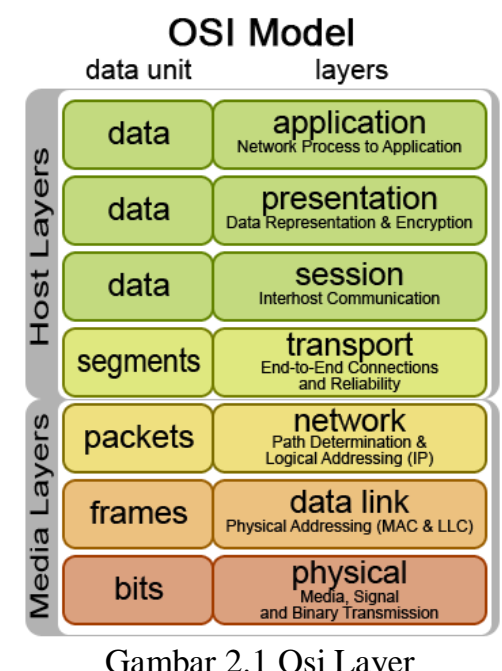

\section{METODE PENELITIAN}

\subsection{Desain Arsitektur Sistem}

Adapun blok diagram dari sistem ini seperti pada Gambar 1 berikut:

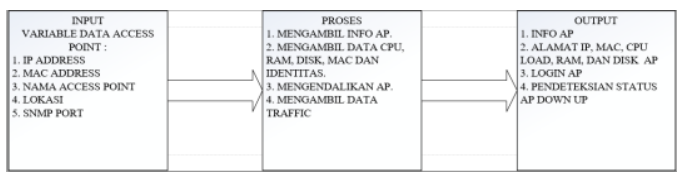

Gambar 3.1. Desain Arsitektur sistem

Pada Gambar 3.1. menunjukkan bahwa data input merupakan data dasar yang digunakan untuk memperoleh informasi suatu perangkat access point.
Data tersebut kemudian di proses untuk kemudian dicocokkan dengan snmp perangkat. Kemudian hasil proses memberikan hasil informasi perangkat secara akurat dan realtime.

\subsection{Topologi jaringan}

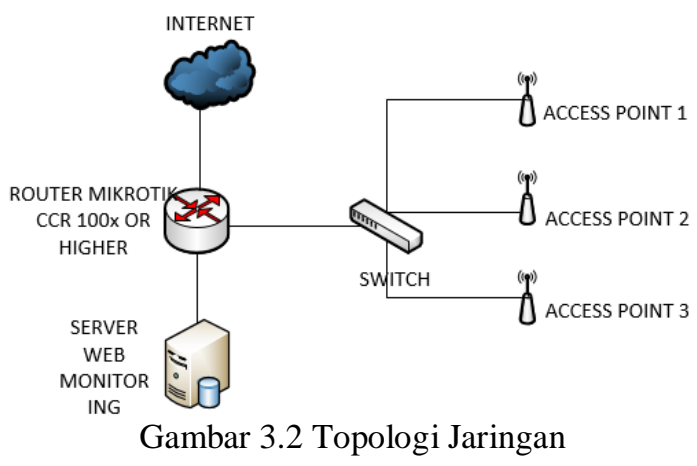

Pada Gambar 3.2. di atas merupakan topologi jaringan yang akan di gunakan dimana Router mikrotik sebgai pusat berkomunikasi antar jaringan access point dengan server web monitoring. Pc server web monitoring di hubungkan dengan router kemudian melakukan routing agar bias mengakses semua ip pada jaringan access point. Setelah semua routing berajalan, disisi lain access point sudah tersambung dengan switch yg terhubung pada router. Berikut Penjelasan Ethernet pada Router mikrotik.

\subsection{Diagram Blok Sistem}

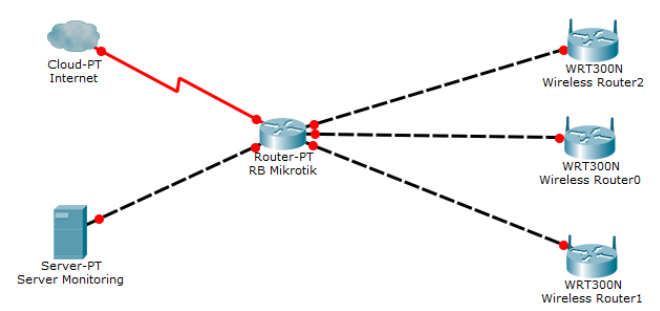

Gambar 3.3 Diagram Blok Sistem

Pada Gambar 3.3. di atas merupakan diagram blok dari alur jalan nya sistem, yang berawal dari login admin untuk membuka sistem web based, kemudian admin dapat mengolah data perangkat dan gedung dari web based yang di buat, dimana data perangkat dan gedung disimpan pada server web monitoring yang sudah terkoneksi dengan router mikrotik. Ketika admin mengakses halaman monitoring maka admin harus memasukkan username dan password terlebih dahulu. Ketika proses otentikasi benar maka admin dapat memanajemen serta memonitoring access point di dalam web monitoring tersebut. 


\subsection{Flowchart Aplikasi}

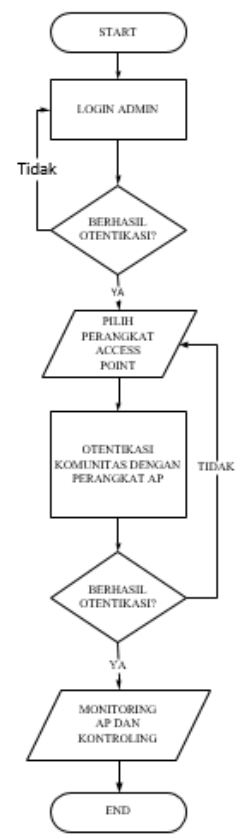

Gambar 3.4 Flowchart Aplikasi

Pada Gambar 3.4 Merupakan flowchart untuk menyambungkan perangkat AP dengan web monitoring admin jaringan. Dimana awal proses dengan melakukan otentikasi login. Kemudian memilih perangkat AP yang ingin di monitor. Setelah perangkat dinyatakan sukses otentikasi maka akan masuk Kedalam halaman monitor dan control perangkat. admin dapat mengontrol perangkat dari jarak jauh menggunakan web service dari perangkat tersebut dalam jarak jauh.

\section{HASIL DAN PEMBAHASAN}

4.1. Pengujian Monitoring Perangkat Access Point

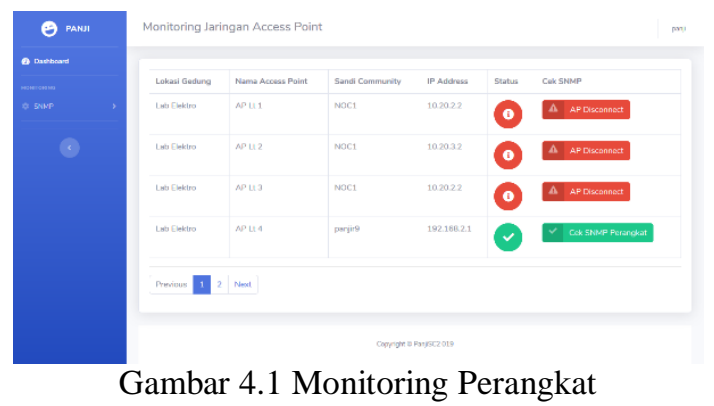

Pada hasil pengujian Digambar 4.1 dilakukan pengujian semula perangkat access point dengan ip 192.168.2.1 dan beberapa perangkat lainnya terpantau dalam kondisi disconnect. Lalu dilakukan pengujian dengan menghidupkan salah satu perangkat tersebut, dan hasil dari pengujian tersebut kondisi dengan ip 192.168.2.1 yang dimonitor melalui website berubah menjadi Connected. (icon berubah menjadi hijau dengan tanda centang).

\subsection{Tampilan Menu Register Monitoring}

Dalam halaman ini tersedia proses CRUD (Create Read Update Delete).

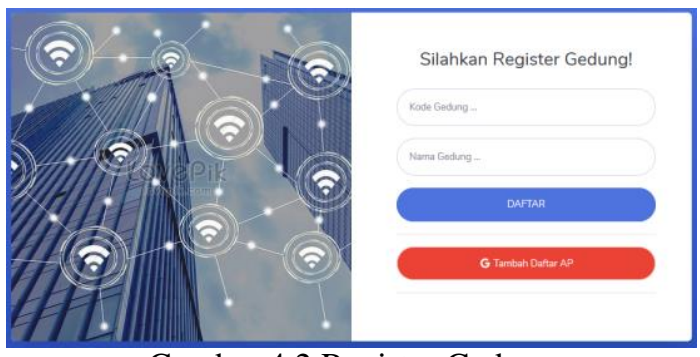

Gambar 4.2 Register Gedung

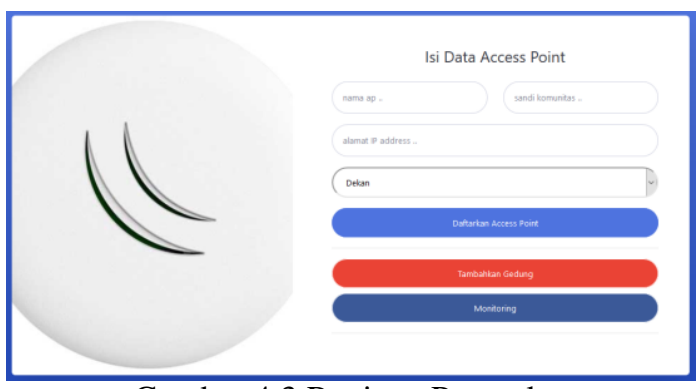

Gambar 4.3 Register Perangkat

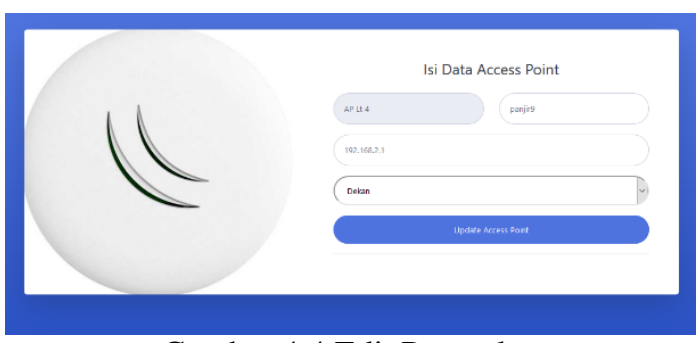

Gambar 4.4 Edit Perangkat

Pada menu ini adalah proses CRUD (Create Read Update Delete) apabila administrator ingin menambahkan server atau ingin melakukan edit dan delete.

\subsection{Tampilan Menu SNMP}

Halaman ini merupakan fungsi utama dari monitoring perangkat access point

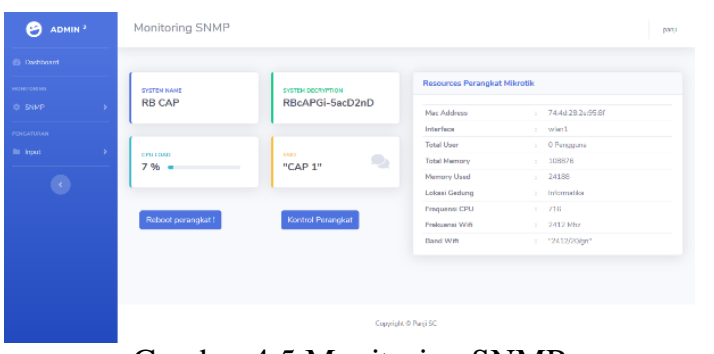

Gambar 4.5 Monitoring SNMP

Pada halaman ini administrator dapat mengetahui data dari suatu perangkat access point dan dapat melakukan pemantauan apakah perangkat perlu di mulai ualang atau bahkan dimatikan. 


\subsection{Log Aktivitas Perangkat}

Pada halaman pengujian log ini akan menampilkan aktivitas dari suatu perangkat tiap harinya.
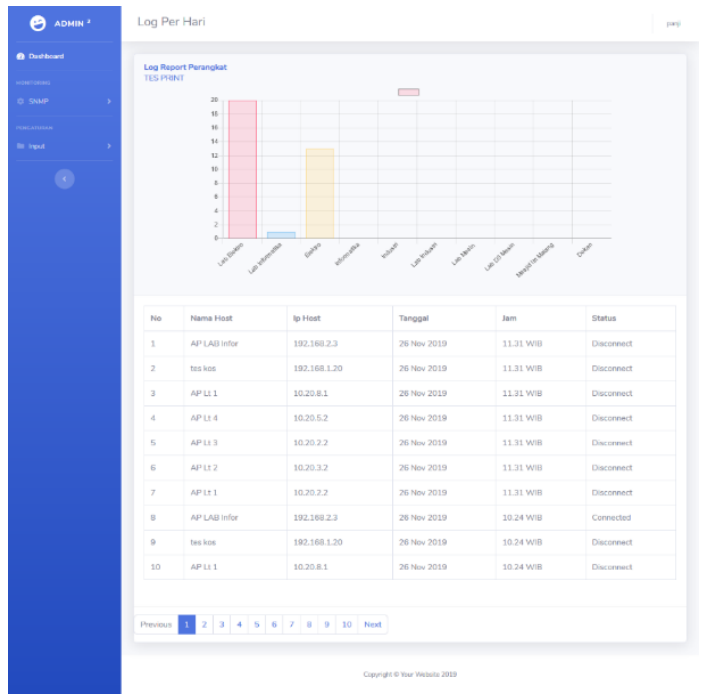

Gambar 4.10 Log Aktivitas

Pada Gambar 4.10 merupakan hasil dari pengujian log otomatis perangkat. Tiap perangkat yang terhubung maupun terputus akan direkam oleh web monitoring. Admin dapat melihat hasilnya tiap hari dan untuk perhitungan adalaha tiap jam.

\subsection{Hasil Pengujian Fungsionalitas Menu}

Pengujian fungsional sistem dilakukan untuk mengetahui apakah fitur - fitur pada aplikasi dapat berjalan dengan baik atau tidak. Hasil pengujian dapat dilihat dari beberapa data di bawah ini.

Table 4.1 Pengujian Fungsional Sistem.

\begin{tabular}{|c|l|c|c|c|}
\hline \multirow{2}{*}{ No. } & \multicolumn{1}{|c|}{ Fungsi } & \multicolumn{3}{|c|}{ Browser } \\
\cline { 3 - 5 } 1. & $\begin{array}{l}\text { Menampilkan } \\
\text { AP yang } \\
\text { tersambung }\end{array}$ & Ya & Ya & Ya \\
\hline & $\begin{array}{l}\text { Menampilkan } \\
\text { menu } \\
\text { Gedung } \\
\text { Lokasi }\end{array}$ & Ya & Ya & Ya \\
\hline 3. & $\begin{array}{l}\text { Menampilkan } \\
\text { CRUD } \\
\text { perangkat }\end{array}$ & Ya & Ya & Ya \\
\hline 4. & $\begin{array}{l}\text { Menampilkan } \\
\text { fungsi SNMP }\end{array}$ & Ya & Ya & Ya \\
\hline 5. & $\begin{array}{l}\text { Mengontrol } \\
\text { Perangkat }\end{array}$ & Ya & Ya & Ya \\
\hline
\end{tabular}

\subsection{Pengujian Monitoring}

Pengujian monitoring perangkat access point pada tiap gedung secara realtime. Apabila perangkat disconnect maka halaman akan menampilkan informasi berupa ikon merah. Hasil pengujian dapat dilihat dari beberapa data dibawah ini.

Table 4.2 Pengujian Monitoring Realtime.

\begin{tabular}{|c|c|c|c|c|}
\hline \multirow{2}{*}{ No } & \multirow{2}{*}{ Nama AP } & \multicolumn{2}{|c|}{$\begin{array}{c}\text { Menampilkan } \\
\text { Status }\end{array}$} & \multirow{2}{*}{ Realtime } \\
\cline { 3 - 4 } & & $\begin{array}{c}\text { Con } \\
\text { nect }\end{array}$ & $\begin{array}{c}\text { Discon } \\
\text { nect }\end{array}$ & \\
\hline 1 & Ap Lt 1 & & $\checkmark$ & Ya \\
\hline 2 & Ap Lt 2 & $\checkmark$ & & Ya \\
\hline 3 & Ap Lt 3 & $\checkmark$ & & Ya \\
\hline 4 & Ap Cap & & $\checkmark$ & Ya \\
\hline 5 & Ap Cap 1 & & $\checkmark$ & Ya \\
\hline
\end{tabular}

\subsection{Pengujian SNMP}

Pengujian snmp merupakan hasil dari pertukaran data informasi dari perangkat dengan web menggunakan protokol snmp. Pada halaman ini admin dapat mengetahui kondisi kesehatan perangkat. Hasil pengujian dapat dilihat dari beberapa data dibawah ini

Table 4.3 Pengujian Monitoring SNMP.

\begin{tabular}{|c|c|c|c|c|c|c|}
\hline \multirow[b]{2}{*}{ No } & \multirow[b]{2}{*}{$\begin{array}{c}\text { Nama } \\
\text { AP }\end{array}$} & \multicolumn{4}{|c|}{ Menampilkan SNMP } & \multirow[b]{2}{*}{ 葛 } \\
\hline & & 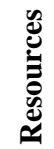 & : & 坣 & 是 & \\
\hline 1 & Ap Lt 1 & $\checkmark$ & $\checkmark$ & $\checkmark$ & $\checkmark$ & $\mathrm{Ya}$ \\
\hline 2 & Ap Lt 2 & $\checkmark$ & $\sqrt{ }$ & $\checkmark$ & $\checkmark$ & $\mathrm{Ya}$ \\
\hline 3 & Ap Lt 3 & $\checkmark$ & $\checkmark$ & $\checkmark$ & $\checkmark$ & $\mathrm{Ya}$ \\
\hline 4 & Ap Cap & $\checkmark$ & $\checkmark$ & $\checkmark$ & $\checkmark$ & $\mathrm{Ya}$ \\
\hline 5 & Ap Cap 1 & $\checkmark$ & $\checkmark$ & $\checkmark$ & $\checkmark$ & $\mathrm{Ya}$ \\
\hline
\end{tabular}

\subsection{Pengujian Email Notifikasi}

Pada setiap perangkat yang terhubung maupun terputus, akan memberikan notifikasi ke email admin. Notifikasi akan terus berjalan tiap jam nya, dan akan merekam aktivitas nya Kedalam log. Hasil pengujian dapat dilihat dari beberapa data dibawah ini.

Table 4.4 Pengujian Notifikasi.

\begin{tabular}{|c|c|c|c|c|c|c|}
\hline \multirow[b]{2}{*}{$\ddot{z}$} & \multirow[b]{2}{*}{$\begin{array}{c}\text { Nama } \\
\text { AP }\end{array}$} & \multicolumn{2}{|c|}{ Status } & \multicolumn{2}{|c|}{$\begin{array}{c}\text { Mengirim } \\
\text { Email }\end{array}$} & \multirow[b]{2}{*}{ 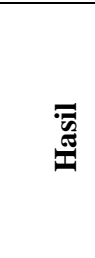 } \\
\hline & & 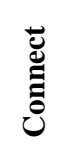 & 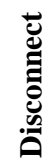 & ن & 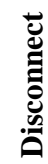 & \\
\hline 1 & Ap Lt 1 & & $\checkmark$ & & $\checkmark$ & Sukses \\
\hline 2 & Ap Lt 2 & $\checkmark$ & & $\checkmark$ & & Sukses \\
\hline 3 & Ap Lt 3 & $\checkmark$ & & $\checkmark$ & & Sukses \\
\hline 4 & Ap Cap & & $\checkmark$ & & $\checkmark$ & Sukses \\
\hline 5 & Ap Cap 1 & & $\checkmark$ & & $\checkmark$ & Sukses \\
\hline
\end{tabular}

\subsection{Pengujian Kontrol Perangkat}

Pada setiap perangkat yang terhubung, akan memberikan fitur pada web untuk memulai ulang perangkat maupun untuk mematikan perangkat. Hasil 
pengujian dapat dilihat dari beberapa data dibawah ini.

Table 4.5 Pengujian Kontrol Perangkat.

\begin{tabular}{|c|c|c|c|c|}
\hline \multirow[b]{2}{*}{ No } & \multirow[b]{2}{*}{ Nama AP } & \multicolumn{2}{|c|}{ Kontroling } & \multirow[b]{2}{*}{$\begin{array}{l}\overline{\overline{5}} \\
\text { 吾 }\end{array}$} \\
\hline & & 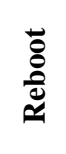 & 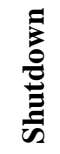 & \\
\hline 1 & Ap Lt 1 & & $\checkmark$ & Sukses \\
\hline 2 & Ap Lt 2 & $\checkmark$ & & Sukses \\
\hline 3 & Ap Lt 3 & $\checkmark$ & & Sukses \\
\hline 4 & Ap Cap & & $\checkmark$ & Sukses \\
\hline 5 & Ap Cap 1 & & $\checkmark$ & Sukses \\
\hline
\end{tabular}

\section{KESIMPULAN DAN SARAN}

\subsection{Kesimpulan}

Berdasarkan Hasil dari Rancang Bangun Sistem Monitoring Access Point Menggunakan Protokol SNMP yang telah dilakukan maka didapat beberapa kesimpulan sebagai berikut:

1. Pembuatan web monitoring menggunakan bahasa program php dan tidak menggunakan library code.

2. Administrator dapat melihat aktifitas dari resources access point pada sistem yang di bangun menggunakan web monitoring access point setelah login dan memasukkan data perangkat access point.

3. Fungsionalitas sistem snmp dalam pengambilan informasi perangkat menggunakan otentikasi ip dan sandi komunitas.

4. Administrator dapat melihat perangkat yang tersambung dan terkoneksi melalui menu awal web monitoring.

5. Administrator dapat melihat berapa jumlah user dan dapat memantau perangkat access point yang terhubung dan terputus dari jaringan tanpa membuka web monitoring.

6. Administrator dapat mempersingkat waktu untuk mengkalibrasi ulang perangkat dalam jarak jauh.

\subsection{Saran}

Adapun saran setelah melakukan pengujian, agar kedepannya sistem ini dapat berjalan lebih baik yaitu sebagai berikut :

1. Sistem memiliki fitur untuk mengetahui kecepatan traffic yang terpakai pada suatu perangkat.

2. Sistem dapat memiliki fitur selain pengontrolan standar access point.

3. System dapat membatasi jumlah user yang masuk pada perangkat access point agar tidak terjadi overload user .

\section{DAFTAR PUSTAKA}

[1] Pradikta, Affandi \& Setijadi,2013,' Rancang Bangun Aplikasi Monitoring Jaringan Dengan Menggunakan Simple Network Management Protocol', Jurnal Teknik Pomits, Vol 2, No. 1, Issn : 2337-3539

[2] Styowati, K. D. 2019. Penerapan Pemancar Koneksi Hotspot Menggunakan Metode Point To Multi Point Pada Layer Data Link Dengan Program Monitoring Telegram. Jurnal Mahasiswa Teknik Informatika, 3(1), 152-157

[3] Faisol, A., \& Muttaqin, I. I. (2018). Implementasi Sensor Monitoring Pada Jaringan Wi-Fi (Hotspot) Berbasis Snort. Jurnal Teknologi Informasi Dan Teraccess pointan, 5(2), 141-146.

[4] Faisol, A. 2017. Implementasi Sms Gateway Sebagai Sistem Monitoring Kinerja Jaringan Komputer. Prosiding Senatek 2015, 1(A), 503507.

[5] Taftazanie, S., Prasetijo, A. B., \& Widianto, E. D. (2017). Aplikasi Pemantau Perangkat Jaringan Berbasis Web Menggunakan Protokol SNMP dan Notifikasi SMS. Jurnal Teknologi dan Sistem Komputer, 5(2), 62-68.

[6] Limpraptono, F. Y., Sotyohadi, S., \& Setiawan, H. (2010). Pengembangan Aplikasi Protocol SNMP Untuk Manajemen Dan Monitoring Peralatan Jaringan Intranet. Jurnal Elektro ELTEK, 1(1), 54-63.

[7] Agustina, R., Yusuf, M. Z., Purnama, I., \& Anwar, M. N. (2013). Monitoring Jaringan Menggunakan Mikrotik OS dan The Dude. Teknologi, 6.

[8] Harkespan, T. D. P., \& Cholil, W. (2013). Analisa Kinerja Wireless Radius Server Pada Perangkat Access Point 802.11 g (Studi Kasus di Universitas Bina Darma). Semantik, 3(1).

[9] Pradikta, R., Affandi, A., \& Setijadi, E. (2013). Rancang Bangun Aplikasi Monitoring Jaringan dengan Menggunakan Simple Network Management Protocol. Jurnal Teknik ITS, 2(1), A154-A159.

[10] Putra, I. E. (2013). Perancangan Jaringan Hotspot Berbasis Mikrotik Router OS 3.3. 0. Jurnal TeknoIf, 1(1).

[11] Indriani Lestariningati Fathur Rozak, S. (2014). Pembangunan aplikasi monitoring jaringan berbasis web menggunakan simple network management protocol (snmp). Majalah Ilmiah UNIKOM. 